\title{
General structure design and field experiment of pneumatic rice direct-seeder
}

\author{
Xing $\mathrm{He}^{1}$, Wang Zaiman ${ }^{1,2}$, Luo Xiwen ${ }^{1,2}$, Cao Xiaoman ${ }^{1}$, Liu Chunbo ${ }^{1}$, Zang Ying ${ }^{1,2^{*}}$ \\ (1. Key Laboratory of Key Technology on Agricultural Machine and Equipment, Ministry of Education, South China Agricultural University, \\ Guangzhou 510642, China; 2. Collaborative Innovation Center for Grain and Oil Crops in South China, Changsha 410128, China)
}

\begin{abstract}
In order to meet the requirement of field direct seeding for super hybrid rice: 1-3 seeds per hill, a pneumatic rice direct-seeder with six seeding metering devices was designed. Transmission system of pneumatic rice direct-seeder and seed metering device were analyzed in this study. And the pipeline structure and vortex pump were designed and selected. The pressure distribution of the pipeline was tested. The pressure value of each sub-pipeline under the conditions of different main pipeline pressure value was obtained and the reasons for pressure loss were analyzed. The results showed that the variation coefficient between sub-pipelines was less than 5\%. The pipeline pressure could be evenly distributed. Further, the field experiments were carried out on super hybrid rice Peizataifeng using two-factor testing, by which the effects of different negative pressure and different forward speed (namely, rotational speed of suction plate) for seeding precision were studied. It found that: (1) the optimal negative pressure was $2 \mathrm{kPa}$; (2) under the optimal negative pressure, the probabilities of 1-3 seeds per hill for the direct-seeder were $93.41 \%, 95.47 \%$ and $97.50 \%$, respectively, when the forward speed of the direct-seeded was high, medium and low speed; (3) the probability of empty hole was less than $2 \%$, which satisfied the field direct seeding requirements of super hybrid rice. Additionally, hill spacing was measured, and the factors affecting the hill spacing were analyzed. The results showed that the fluctuation of hill spacing in the small range will not affect the seeding effect. In this study, a new type of pneumatic rice direct-seeder was designed. The main working components were tested and analyzed. The best parameters of field work were obtained. It provides the basis for the field application of the pneumatic rice precision seeder.
\end{abstract}

Keywords: agricultural machinery, rice, pneumatic rice direct-seeder, field experiment, pipeline DOI: $10.25165 /$ j.ijabe.20171006.3142

Citation: Xing H, Wang Z M, Luo X W, Cao X M, Liu C B, Zang Y. General structure design and field experiment of pneumatic rice direct-seeder. Int J Agric \& Biol Eng, 2017; 10(6): 31-42.

\section{Introduction}

Rice is the staple food for more than half of the global population, and the rice production, especially planting, needs a lot of labor force, material and financial resources. The mechanization of rice direct seeding can eliminate

Received date: 2016-12-20 Accepted date: 2017-06-05

Biographies: Xing $\mathrm{He}, \mathrm{PhD}$ candidate, research interests: agricultural mechanization and automation, Email: 675974347@ qq.com; Wang Zaiman, Associate Researcher, research interests: agricultural mechanization and automation, Email: wangzaiman@scau.edu.cn; Luo Xiwen, Professor, CAE Academician, research interests: agricultural mechanization and automation, Email: xwluo@ scau.edu.cn; Cao Xiaoman, PhD candidate, research interests: agricultural electrification and rice seedlings and save the labor and material consumption. With the capability of guaranteeing the yield, direct seeding of rice is one of the important development directions of rice mechanization in China. At present, more than $50 \%$ of China's rice acreage is planting hybrid rice. Super hybrid rice, a kind of hybrid

automation, Email: xiaomancao126@sina.cn; Liu Chunbo, Graduate student, research interests: agricultural electrification and automation, Email: 515096094@qq.com.

*Corresponding author: Zang Ying, PhD, Professor, research interests: Agricultural mechanization and automation. South China Agricultural University, Key Laboratory of Key Technology on Agricultural Machine and Equipment, Ministry of Education, Guangzhou 510642, China. Tel: +86-13902277193, Email: yingzang@scau.edu.cn. 
rice, has stronger tillering ability than ordinary hybrid rice. By using direct seeding technology, the high yield population structure can be formed with only 1-3 seeds per hole. Therefore, precision is a key element of design of the seeding machine ${ }^{[1-3]}$.

The mechanization of rice direct seeding technology mainly includes mechanical sowing, mechanical drilling and hill-direct-seeding. Normally, it is difficult to control the precision of mechanical sowing and mechanical drilling, which lead to uneven seedling distribution, and affect the growth and field management of rice. However, hill-direct-seeding technology has improved the disadvantages of the planting methods. The mechanical rice hill-direct-seeder developed by Luo Xiwen $^{[4]}$ from South China Agricultural University, has been widely used in more than 20 provinces in China and 6 countries such as Thailand. But it was mainly adapted to conventional rice and ordinary hybrid rice seeding, and the precision was generally 3-8 seeds per hole, and it is difficult to meet the requirement of super hybrid rice direct seeding.

Recently, pneumatic seeding machine has been widely studied. Yang et al. ${ }^{[5]}$ reported a pneumatic rapeseed seeding system and an optimal speed of the seeding plate and vortex pump. Li et al. ${ }^{[6]}$ analyzed the 2BQ pneumatic seeder by using the kinematics simulation, to optimize the structure of the seeder and reduce the costs. Zhao et al. ${ }^{[7]}$ designed a suction type offset double disc seed-metering device of soybean seeder, and obtained the optimal air speed. Yasir et al. ${ }^{[8]}$ developed a pneumatic precision seeder for wheat. The theoretical analysis was carried out on three stages: absorption, protection and drop sowing. By using the method of dynamics and kinematics, the experimental verification was carried out, which provided the reference basis for improving the performance of a pneumatic seed metering device. Singh et al. ${ }^{[9]}$ studied and optimized the pneumatic seed-metering device, in which an experimental study was conducted on the suction hole size and shape. The experiment and analysis were performed with the combination of conical and cylindrical suction holes. Indoor and field experiments were undertaken using cotton seeds as the experimental object. The optimal angle of the cone angle, the distance of grain size and the seeding precision were obtained. Liao et al. ${ }^{[10]}$ designed an inside-filling pneumatic precision centralized seed-metering device for rapeseed. Tests were conducted to optimize the work parameters. Yazgi et al. ${ }^{[11,12]}$ optimized the vacuum-type precision seeder using response surface methodology, and conducted tests of the seed spacing. The optimum levels of the variables were verified. Gaikwad et al. ${ }^{[13]}$ designed the low-cost pneumatic vegetable seeder for nursery plug trays. The total cost of sowing is only $15.3 \%$ of the estimated cost of manual sowing. Guarella et al. ${ }^{[14]}$ studied the performance of a vacuum seeder for vegetable seed. The experimental and theoretical methods were adopted for seeder tests. St Jack et al. ${ }^{[15]}$ developed a 'vacuum disc' seed metering device for sandalwood, and the effect of the diameter of holes was analyzed. It verified that the mechanization of sandalwood seed sowing was possible. Karayel et al. $^{[16-19]}$ researched the vacuum pressure of a precision vacuum seeder and established mathematical models by using the physical properties of seeds. The parameter of seeder was optimized by tests in the field and laboratory. The experiment of seed spacing was carried out with high-speed camera system. Ismet et al. ${ }^{[20]}$ developed a nomogram using equations describing the technical characteristics of the seeder. The optimum number for holes was obtained by tests of sticky belt in the laboratory. Ozmerzi et al. ${ }^{[21]}$ researched the effects of different depths of sowing maize on precision vacuum seeder.

The above researches mainly aim at corn, soybean, rape and other crops, while the research on rice pneumatic seeder is still in the research and development stage.

In order to meet the seeding requirement of super hybrid rice, like 1-3 seeds per hole, a kind of pneumatic rice direct seeder was designed in this study based on the pneumatic seed metering device developed by South China Agricultural University ${ }^{[22,23]}$. The experimental investigation and analysis on the pipeline of direct seeder were carried out, and the optimal seeding condition was obtained by utilizing super hybrid rice variety of 'Peizataifeng'. The main objectives of this study were: 
(1) Vortex pump was selected for pneumatic rice direct seeder. The designed pipeline was required to distribute the air pressure uniformly and stably. This provided a basis for the pipeline structure design of pneumatic rice direct seeder.

(2) Field experiments were used to investigate the optimum negative pressure to meet the requirement of super hybrid rice direct seeding by pneumatic rice direct-seeder. Affecting factors of the hill spacing and the effects of hill spacing on the yield were analyzed. It is served as the basis for practical application of the pneumatic rice direct seeder.

\section{Configuration and working principles of the pneumatic rice direct seeder}

\subsection{Configuration}

The configuration of the pneumatic rice direct seeder $^{[24]}$ is shown in Figure 1. The pneumatic rice direct seeder mainly consisted of 2Z-6A(PG6D) rice transplanter, power output shaft, reduction gearbox, chain-drive, precision pneumatic rice seed-metering device, ditching equipment, positive pressure pipeline, negative pressure pipeline, and an integrated gasoline engine vortex-pump. The number of precision pneumatic rice seed metering devices is 6 .

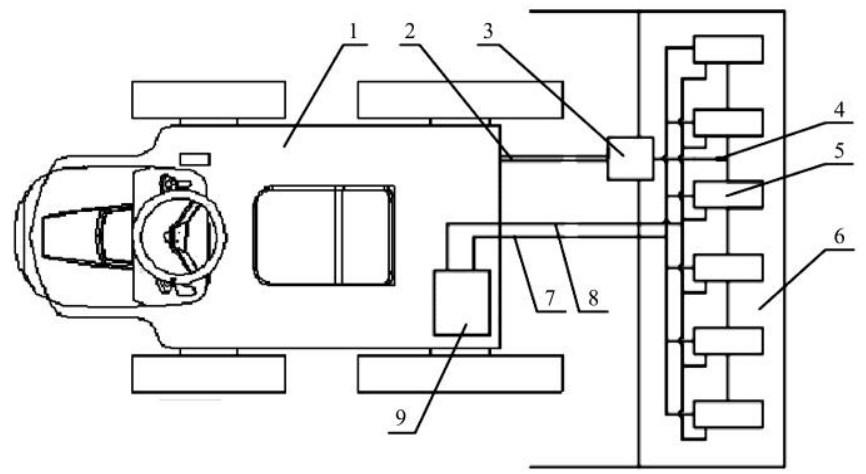

1. 2Z-6A(PG6D) rice transplanter 2. Power output shaft 3. Reduction gearbox 4. Chain-drive 5. Precision pneumatic rice seed metering device 6. Ditching equipment 7. Positive pressure pipeline 8 . Negative pressure pipeline 9. Integrated gasoline engine vortex-pump

Figure 1 Configuration of the pneumatic rice direct seeder

The three-point linkage systems are composed of an upper pull rod and two drop-down rods. It can achieve the seeder stable lifting and falling through the three-point linkage system. A horizontal feeler mechanism is arranged on the ditching equipment. When the seeder is working in the field, the feeler mechanism can adjust height according to the ups and downs of the mud. The front part of ditching equipment is arc shape. It can reduce the seeder resistance, which is caused by mud at work. Problems such as accumulation of clay on the ditching equipment are avoided. The positive and negative pressure pipelines were installed on the upper shelf of ditching equipment. When the seeder is working, it will not interfere with other devices, avoiding the damage of pipeline. The seed metering device is arranged on the shelf in the middle of the ditching equipment and below the whole pipeline, which is convenient to connect with the pipeline.

\subsection{Working principle of pneumatic rice direct seeder}

As shown in Figure 1, the seeding part of the pneumatic rice direct seeder is linked on the 2Z-6A(PG6D) rice transplanter by a three-point linkage system. The power is provided by a power output shaft of the transplanter, and transmitted to the seed-metering device through the chain transmission after the deceleration through the reduction gearbox. The shafts of every pneumatic rice seed-metering device are connected with a coupling to ensure the synchronism of the rotation. An integrated gasoline engine vortex-pump is used as the air power source. The positive and negative pressure pipeline is designed to deliver air, through the pneumatic rice seed-metering device, which is connected with the integrated gasoline engine vortex-pump. The ditching equipment is used to create the sowing ditch and the water ditch. When working, seeds fall into the sowing ditch, and the water is held in the water ditch to ensure that the field surface is wet.

\subsection{Transmission system}

The power is provided by a power output shaft of the 2Z-6A(PG6D) rice transplanter. According to the number of seedling claw and group holes on the sucking plate, the transmission ratio of the power output shaft and the seed metering device is adjusted to $1: 9$, ensuring the relationship between the hill spacing and the planting spacing of transplanter is one-to-one correspondence. The speed of the seed metering device and the advance speed of the transplanter are shown in Equation (1): 


$$
n=6000 \frac{v}{K l}
$$

where, $n$ is speed of the seed metering device, r/min; $v$ is advance speed of the transplanter, $\mathrm{m} / \mathrm{s} ; K$ is the number of group holes on the sucking plate; $l$ is hill spacing, $\mathrm{cm}$.

According to Equation (1), with the same hill spacing, the faster the advance speed of the seeder is, the higher the rotation speed of the seed metering device. With the same advance speed of the seeder, the bigger the hill spacing, the lower the rotation speed of the seed metering device.

\subsection{Pneumatic rice seeding metering device}

The core component of pneumatic rice direct-seeder is pneumatic rice seed metering device. The seed metering device is shown in Figure 2.

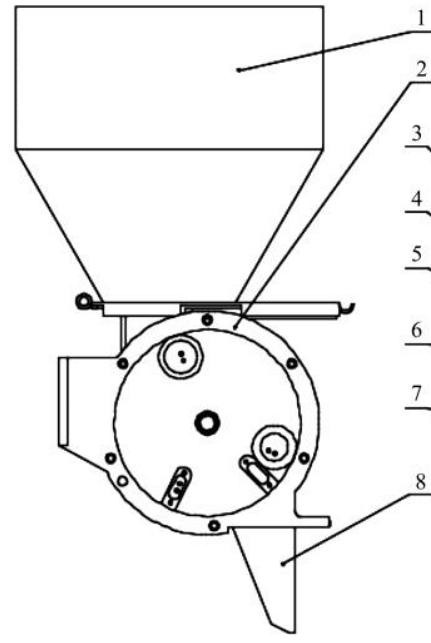

a. Plan view

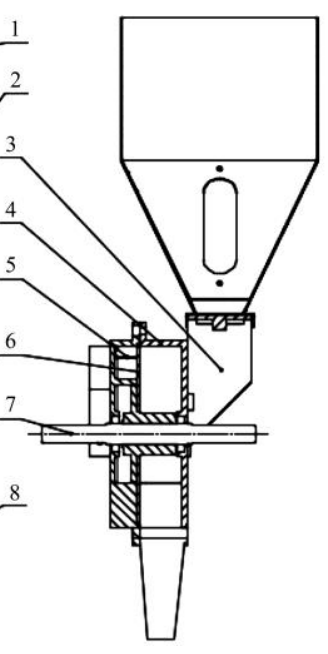

b. Side view
1. Seed box 2. Sucking chamber shell 3. Stratified room 4. Seed chamber shell 5. Cleaning device 6 . Sucking plate 7. Shaft 8 . Seed tube

Figure 2 Configuration of pneumatic rice seed metering device

The precision rice seed metering device mainly consists of seed box, sucking chamber shell, stratified room, seed chamber shell, cleaning device, sucking plate, shaft and seed tube. When the seed metering device is operated, the seeds are getting into the seed filling room of the seed chamber shell through seed box and stratified room. The seed filling room is filled with seeds and then seeds accumulate on the surface of sucking plate. Seeds are sucked on the holes of sucking plate under the effect of vacuum of sucking chamber shell. Because of the low degree of sphericity and surface smoothness of rice seeds, it is difficult to precisely control the number of sucked seeds. These reasons will lead to multiple seeds sucked in a hole. In order to further improve the phenomenon, the seed cleaning device is installed in the seed metering device. The seed cleaning device is shown in Figure 3.

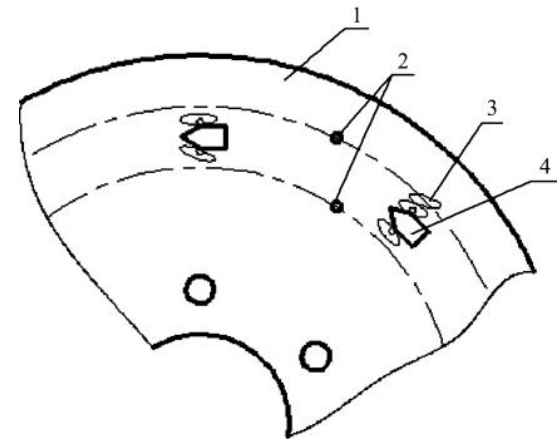

1. Sucking plate 2. Clearing finger 3 . Sucking hole 4 . Churning tooth

Figure 3 Position of seed clearing device

The two clearing fingers are perpendicular to surface of sucking plate, and length of each clearing finger is $40 \mathrm{~mm}$. There is a gap of $0.1 \mathrm{~mm}$ between the clearing fingers and the sucking plate. This gap can prevent mechanical interference when the seed plate rotates. The gap is much smaller than the size of the seed, and seeds will not leak out. The clearing fingers are located on the outer side of the 2 suction holes, $4 \mathrm{~mm}$ away from the center of the hole. If the distance between hole center and clearing fingers is too close, it will cause excessive clearing. When the seed metering device is running, seeds flowed from the seed box, then through stratified seed-filling room towards filling room of seed chamber shell. Then seeds were sucked into sucking holes of sucking plate under the negative pressure of vacuum chamber. These seeds rotated as the rotation of shaft. The multiple sucked seeds are cleaned by the cleaning device in clearing place. Seeds then rotated into carrying place and were blown away from sucking plate under the positive pressure, dropping into the seed tube. The process of seeding is finished after seeds fell into seed furrow from the seed tube.

The seeding plate has a circle of about $165 \mathrm{~mm}$ diameter and a thickness of $2 \mathrm{~mm}$. There are 8 sets of group holes on the sucking plate. Every set of group holes is consisted of two sucking holes. Two sucking holes in one set are linear distribution along the radial direction of the sucking plate. The distance between two sucking holes was $6.5 \mathrm{~mm}$. The position of the hole inside of one set was in a circle of $61.5 \mathrm{~mm}$ radius, with the center of seeding plate as rotary center. The 
churning tooth was installed between two sucking holes.

Two sides of the sharp corner of churning tooth were tangent to the outer circles of two sucking holes. Churning tooth was distributed equally along sucking holes. The diameter of sucking hole is $1.5 \mathrm{~mm}$. But the sucking plate thickness is very thin. The depth of sucking hole is very short. Meanwhile, there are two bristle clearing devices installed in the sucking chamber shell and one bristle clearing devices installed in the seed chamber shell. Positive pressure is used to blow seeds in dropping place. Therefore, problems such as electrostatic interference and blocked sucking hole are prevented, as shown in Figure 4.

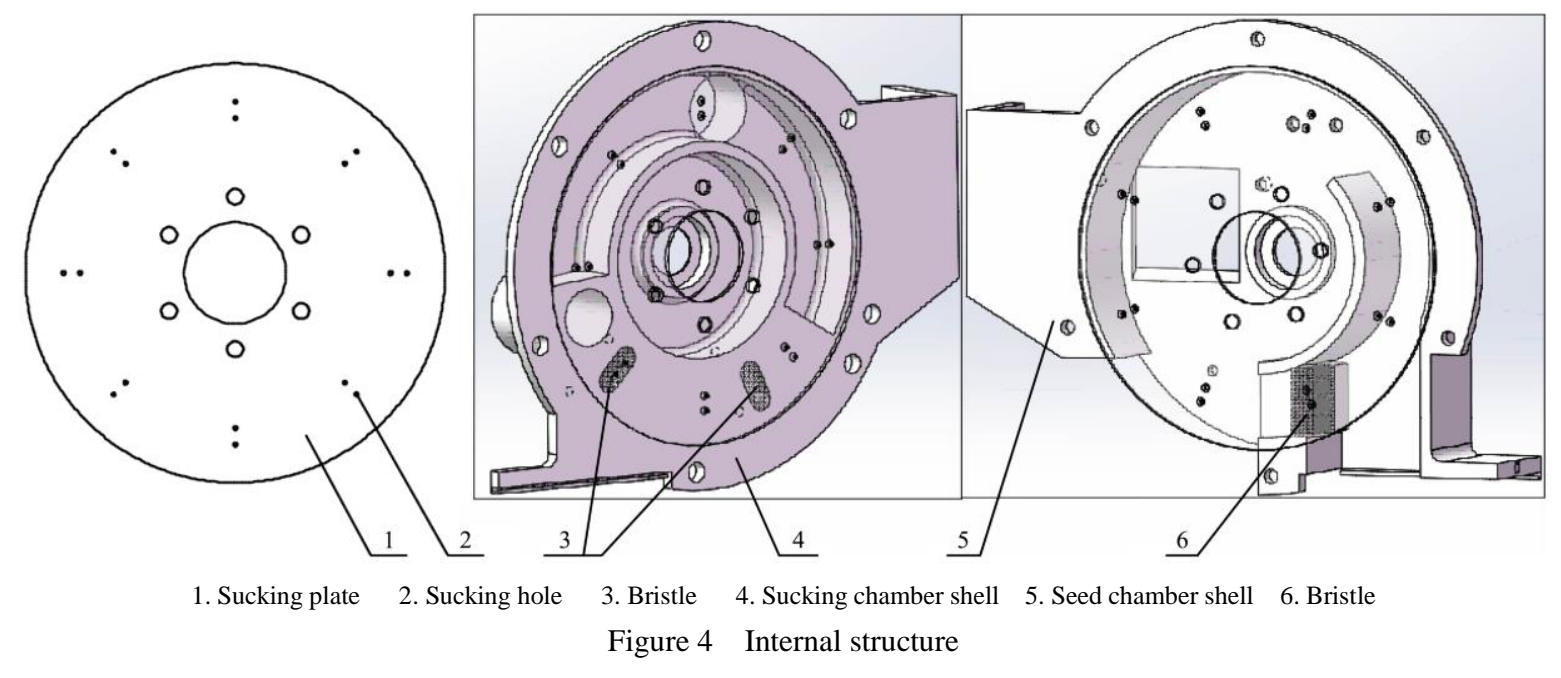

\section{Vortex pump selection and pipeline experiment}

\subsection{Vortex pump selection}

According to the past study ${ }^{[23]}$, the optimal negative pressure for a single seed-metering device is $1.6 \mathrm{kPa}$.

In this research, the pipeline was PVC pipe with an inner diameter of $36 \mathrm{~mm}$ and an outside diameter of $40 \mathrm{~mm}$. The experiment was carried out at the optimal negative pressure of $1.6 \mathrm{kPa}$. The air speed of a single seed-metering device was measured by anemometer and the result was $6.6 \mathrm{~m} / \mathrm{s}$. As the air flow rate is low, it can be considered as incompressible gas. According to the formula of fluid mechanics ${ }^{[25]}$, Equation (2), the flow rate of a single seed-metering device was $24.2 \mathrm{~m}^{3} / \mathrm{h}$.

$$
Q=A \cdot v
$$

where, $Q$ is the flow rate, $\mathrm{m}^{3} / \mathrm{s} ; A$ is the cross-section area of the pipe, $\mathrm{m}^{2} ; v$ is flow velocity, $\mathrm{m} / \mathrm{s}$.

Therefore, the minimum flow rate to meet the requirement of six seed-metering devices working at the same time was $145.2 \mathrm{~m}^{3} / \mathrm{h}$. Due to the complexity of the field conditions, machine vibration and other factors would affect the reliability of the seed-metering device. It was necessary to increase the flow rate to ensure the normal operation of the seed metering device. Thus, the vortex pump was chosen with the output flow $200 \mathrm{~m}^{3} / \mathrm{h}$, positive pressure of $30 \mathrm{kPa}$ and negative pressure of $-29 \mathrm{kPa}$.

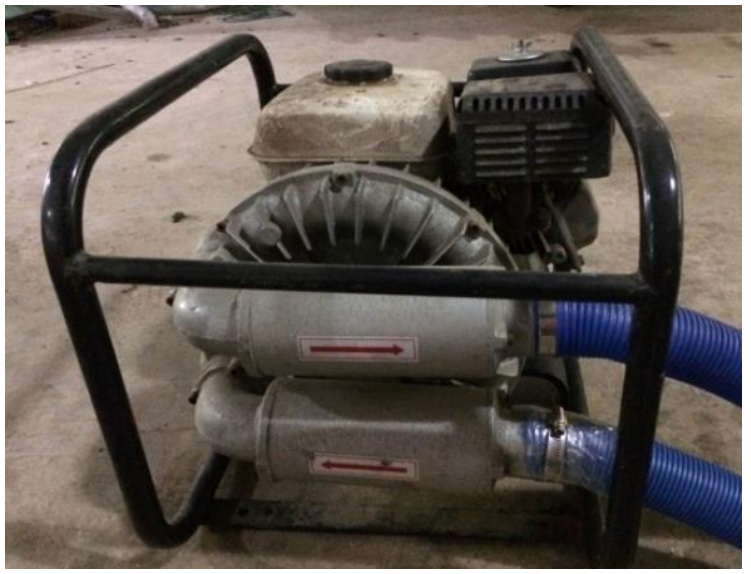

Figure 5 Integrated gasoline engine vortex-pump

Because of limited output power of 2Z-6A(PG6D) rice transplanter, $8 \mathrm{~kW}$, it was difficult to provide enough power for the vortex pump, for which an external power equipment was needed to provide power. As the installation position of the 2Z-6A(PG6D) was limited, it was necessary to reduce the volume of external devices as much as possible. Therefore, an integrated gasoline engine vortex-pump was used as the air engine to provide air source for seed-metering device, as shown in Figure 5. 
The device consisted of a vortex pump and a gasoline engine. The overall dimensions were $304 \mathrm{~mm} \times 362 \mathrm{~mm}$ $\times 335 \mathrm{~mm}$ (length $\times$ width $\times$ height) and the quality was $30 \mathrm{~kg}$. The gasoline engine power was $4 \mathrm{~kW}$, providing the power for the vortex pump. The volume of the device was small and suitable for the pneumatic rice direct seeder.

\subsection{Structural design and experiment of pipeline}

The positive and negative pressure interfaces of pneumatic rice metering device were both $40 \mathrm{~mm}$. According to the fluid mechanics, changes in pipe diameter would bring loss of partial pressure, and the greater the change of pipe diameter the greater the loss of partial pressure. Therefore, PVC pipe of $40 \mathrm{~mm}$ was used to connect with the positive and negative pressure interface of the seed-metering device to reduce the loss of partial pressure caused by the change of pipeline diameter.

According to the agronomic requirements of super hybrid rice, the rice spacing was set at $250 \mathrm{~mm}$, namely, the interval between the seed-metering devices was $250 \mathrm{~mm}$. The row spacing was fixed at $250 \mathrm{~mm}$.

If each seed-metering device was directly connected with the integrated gasoline engine vortex-pump, and a large cavity is needed in order to distribute the flow rate. As mentioned before, the loss of partial pressure would occur when the air flowed into the cavity from the pipeline. Meanwhile, the direct connection between the seed-metering device and the integrated gasoline engine vortex-pump will lead to the increase of overall length of pipeline and pressure loss. These two factors would increase the pressure loss, which is unfavorable to the pressure distribution, and even affect the normal work of the seed-metering device.

Therefore, the design should minimize the pipe diameter and bending, to decrease the loss of partial pressure. The length of pipeline should also be shortened as much as possible, which can reduce the pressure loss along the way. In this study, the parallel shunt type pipeline was used to distribute the air source for the seed-metering device. The main pipeline was in the middle position and extended to both ends. Each seed metering device was installed in the sub-pipeline that was connected with the main pipeline, as shown in Figure 6. The pipeline has a diameter of $40 \mathrm{~mm}$ and the entire pipeline has the same diameter, so as to avoid the loss of partial pressure caused by changing diameter. The bending of pipeline was eliminated, owing to the linear arrangement of the pipeline. Each seed-metering device was connected with a pipeline in a straight line, and the length of pipeline was shortened, to avoid the pressure loss along the way. The $40 \mathrm{~mm}$ diameter tees and elbows were used to splice the pipeline, and the joints were sealed with sealant to prevent leakage. The whole pipeline is symmetrically distributed in the center of the main pipeline, and ensures the equal spacing between each sub-pipeline. Meanwhile, the sub-pipelines are connected with seed metering devices to provide a passage for the air flow, ensuring the normal operation of the seed metering device.

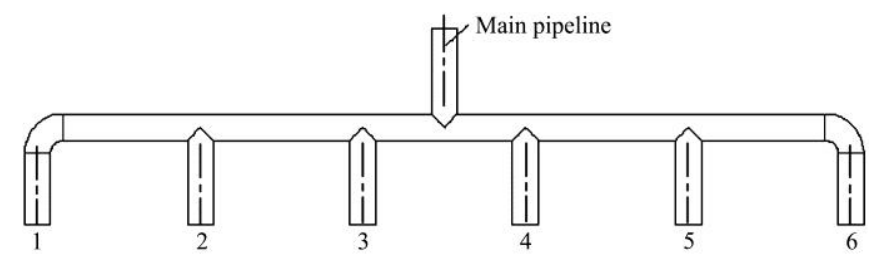

Note:1-6: Sub-pipeline

Figure 6 Pipeline

Because all air sources of seed metering devices were powered by the integrated gasoline engine vortex-pump, the distribution of airflow was particularly important. In order to study the uniformity and stability of the pressure distribution of pipelines, the experiments were carried out under different negative pressure of the main pipeline. The pressure value of each sub-pipeline was measured by the horizontal pressure gauge. In addition, the horizontal pressure gauge was used to measure the pressure accurately. Firstly, a threaded hole was arranged on the pipeline. Then threaded joint was installed in the threaded hole. Waterproof tape was wrapped around threaded joint to prevent pressure leakage from the threaded hole. The rubber hose was used to connect the joint with the horizontal pressure gauge. Pressure value will be measured in this way. The test results are given in Table 1. The average value of the pipeline experimental pressure are fitted and analysed. The fitting equation is $y=0.2368 x+0.513, R^{2}=0.998$. The fitting effect is good. It can be used to predict 
pressure value of sub-pipeline under known the pressure value of main pipeline.

Table 1 Experiment results of negative pressure pipeline

\begin{tabular}{|c|c|c|c|c|c|c|c|c|}
\hline \multirow{2}{*}{$\begin{array}{l}\text { Main pipeline } \\
\text { negative } \\
\text { pressure/kPa }\end{array}$} & \multicolumn{7}{|c|}{ Sub-pipeline pressure/kPa } & \multirow{2}{*}{$\begin{array}{c}\text { Coefficient } \\
\text { of } \\
\text { variation/\% }\end{array}$} \\
\hline & 1 & 2 & 3 & 4 & 5 & 6 & Average & \\
\hline 1.5 & 0.7 & 0.7 & 0.75 & 0.75 & 0.72 & 0.7 & 0.72 & 3.40 \\
\hline 2.0 & 1.0 & 1.0 & 1.05 & 1.05 & 1.0 & 1.0 & 1.02 & 2.54 \\
\hline 2.5 & 1.15 & 1.25 & 1.30 & 1.28 & 1.22 & 1.20 & 1.23 & 4.46 \\
\hline 3.0 & 1.45 & 1.45 & 1.48 & 1.50 & 1.45 & 1.45 & 1.46 & 1.48 \\
\hline 3.5 & 1.65 & 1.65 & 1.75 & 1.78 & 1.65 & 1.65 & 1.69 & 3.56 \\
\hline 4.0 & 1.90 & 1.90 & 1.95 & 1.97 & 1.95 & 1.90 & 1.93 & 1.65 \\
\hline
\end{tabular}

It can be seen from Table 1 that under different negative pressure of the main pipeline, the negative pressure of the pipeline is basically stable and the variation coefficient is less than 5\%. Since the source of air pressure is provided by the middle pipeline, air pressure of sub-pipelines (No. 3 and No. 4) close to the main pipeline is slightly higher, and the air pressure at both ends is slightly lower. The reason is that air is fluid with a certain viscosity, and the pressure loss will occur when the air flows in the pipeline. The low viscosity of air, the short length of pipeline and the small bending of the pipeline will result in a small pressure loss. When the air pressure of the main pipeline was higher than $3.5 \mathrm{kPa}$, the air pressure of each sub-pipeline was higher than $1.6 \mathrm{kPa}$, which can meet the requirement of a single seed-metering device under the condition of the laboratory.

\section{Field experiments and analysis for pneumatic rice direct seeder}

\subsection{Experiment materials}

In order to study the optimal conditions of field sowing, field experiment was conducted on the pneumatic rice direct seeder.

Experimental material was the hybrid rice of Peizataifeng that widely planted in south China. The average size of seed was $8.94 \mathrm{~mm} \times 2.30 \mathrm{~mm} \times 1.94 \mathrm{~mm}$ (length $\times$ width $\times$ thickness), and the weight of 1000-grain was $22.4 \mathrm{~g}$. The sliding friction angle was $24.8^{\circ}$. The dry seeds were soaked in clear water for $24 \mathrm{~h}$. After that, they were moistened to bud and then filtered out and dried. The average moisture content was $21.4 \%$ (wet basis) before the test. The experiment was in August 3, 2015 morning, and the local temperature is $30^{\circ} \mathrm{C}$.
The experiment was located in Cen Cun Experimental Farm of South China Agricultural University. Before the test, the field had been soaked for $2 \mathrm{~d}$, and the rotary cultivator was used to plow the field with water two times until there was mud in the field. The laser land leveling machine was used for leveling the paddy field. Mud had been precipitated for two days before seeding. The field was ditched with good effect after precipitation of paddy field, to facilitate recording data after seeding. The field experiment of the prototype is shown in Figure 7.

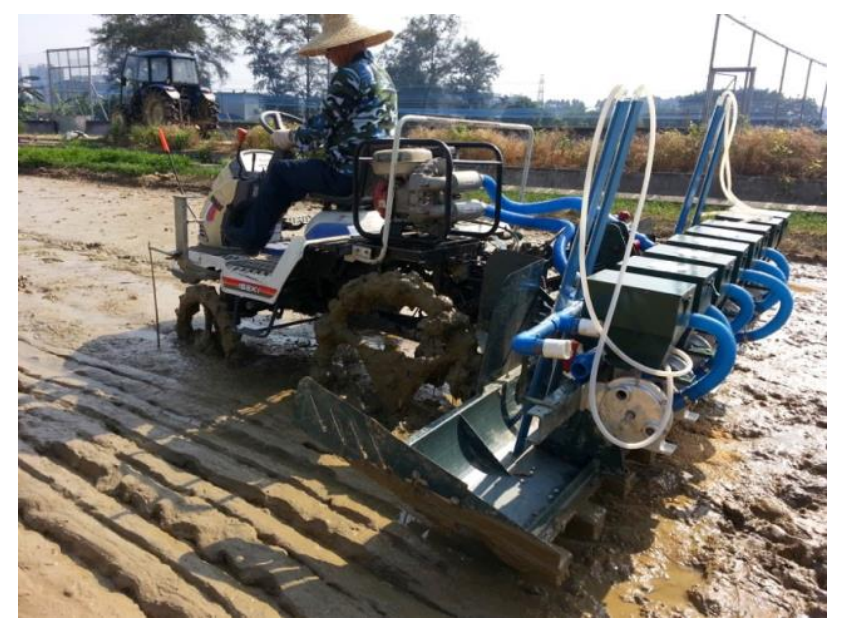

Figure 7 Field experiment

\subsection{Evaluation and calculation methods}

\subsubsection{Evaluation Index}

In order to meet the agronomic requirements of super hybrid rice growth, $2 \pm 1$ seeds per hole (namely, 1-3 seeds per hole) were taken as the standard. The probabilities of 1-3 seeds per hole (the number of $(2 \pm 1)$ seed per holes/the total number of holes $\times 100 \%$ ) were set as the evaluation index.

\subsubsection{Calculation methods}

Reference to the regulations of Chinese National Standard (GB/T 6973-2005) ${ }^{[26]}$, the quantity of total seeds per hole was considered as $X_{k}$. were successively recorded. Every 200 times were regarded as a group, and three sets of the data were obtained. Thus, the average quantity of seeds per hole $(\bar{X})$ could be calculated as in Equation (3):

$$
\bar{X}=\frac{1}{600} \sum_{j=1}^{3}\left(\sum_{k=1}^{200} X_{k}\right)
$$

where, frequency of $0,1,2,3$, or more seeds per hole from $X_{i}$ was investigated as $x_{t}$. Thus, sucking probability $p(i)$. For different seed quantity per hole could be calculated by Equation (4): 


$$
p(i)=\frac{\sum_{j=1}^{3} \chi_{i j}}{600}, i=0,1,2,3,4,5,6, \ldots, 200 ; j=1,2,3
$$

\subsection{Experimental design}

In order to observe the test results clearly, the hill spacing of test prototype was fixed at $150 \mathrm{~mm}$, and negative pressure of $1.6 \mathrm{kPa}$ and positive pressure of $0.1 \mathrm{kPa}^{[23]}$. Therefore, the positive pressure was fixed at $0.1 \mathrm{kPa}$, and the field experiments were carried out under different negative pressure and different forward speed (the rotational speed of the seeding plate). Due to the complexity of field conditions, the minimum negative pressure of seeder was fixed at $1.8 \mathrm{kPa}$, which was slightly higher than the optimal negative pressure in the laboratory. It can reduce the impact of the mechanical vibration and other factors, and improve the reliability of the seed suction simultaneously.

Depending on the experimental results, the distribution of air pressure was uniform. Therefore, the outermost seed-metering device was chosen to measure the pressure. Considering the pressure of the pipeline at the middle was slightly higher than that at two ends, therefore, when the pressure of outermost device can meet the requirement of seeding, the pressure of middle device can meet the requirement as well. The pressure values described below are the pressure values measured at the outermost seed-metering device.

The forward speed was divided into three groups: high speed, middle speed and low speed, through seeder gearshift adjusting. The preliminary field experimental results showed that the low speed was between 0.2$0.3 \mathrm{~m} / \mathrm{s}$ (the equivalent speed of seeding plate was about $15 \mathrm{r} / \mathrm{min}$ ); the medium speed was between $0.5-0.6 \mathrm{~m} / \mathrm{s}$ (the equivalent speed of seeding plate was about $30 \mathrm{r} / \mathrm{min}$ ); the high speed was between $0.8-0.9 \mathrm{~m} / \mathrm{s}$ (the equivalent speed of seeding plate was about $50 \mathrm{r} / \mathrm{min}$ ).

Two-factor test method was used in the present experiment. The influential factors and levels are given in Table 2. Every 200 holes were taken as a group, and the test was repeated three times. The seeding quantity of each seed-metering device was recorded and analyzed by SPSS software ${ }^{[27]}$.

Table 2 Experimental factors and levels

\begin{tabular}{ccc}
\hline \multirow{2}{*}{ Level } & \multicolumn{2}{c}{ Factor } \\
\cline { 2 - 3 } & A negative pressure/Pa & B forward speed \\
\hline 1 & 1800 & Low $\left(0.2-0.3 \mathrm{~m} \cdot \mathrm{s}^{-1}\right)$ \\
2 & 2000 & Middle $\left(0.5-0.6 \mathrm{~m} \cdot \mathrm{s}^{-1}\right)$ \\
3 & 2200 & High $\left(0.8-0.9 \mathrm{~m} \cdot \mathrm{s}^{-1}\right)$ \\
\hline
\end{tabular}

\subsection{Results and analysis}

The experimental results are given in Table 3.

The results indicated that under the negative pressure of $1.8 \mathrm{kPa}$, the probabilities of empty seed were $1.16 \%$, $2.74 \%$ and $6.83 \%$, respectively. The vibration would increase as the forward speed of seeder increases, which would impact on sucking capacity of seeder. The vibration would force sucked seeds to leave the suction hole of seeds suction plate. At the same time, the centrifugal force would increase when the speed of suction plate increases, then the seeds leaving the suction hole. Thus it results in the probabilities of empty seed. The probabilities of 1-3 seeds per hole would decrease as the forward speed of seeder increases; the probabilities of $\geq 4$ seeds per hole remained at around 5\%. Therefore, $1.8 \mathrm{kPa}$ of negative pressure can meet the requirements of low speed seeding, but cannot satisfy the demand of high speed seeding.

Table 3 Field experiment results

\begin{tabular}{|c|c|c|c|c|c|c|c|c|}
\hline \multirow{2}{*}{ No. } & \multicolumn{2}{|c|}{ Level of factor } & \multirow{2}{*}{$\begin{array}{l}\text { Missed seed } \\
\text { per hole }\end{array}$} & \multirow{2}{*}{$\begin{array}{l}\text { 1-3 Sucked seeds } \\
\text { per hole }\end{array}$} & \multirow{2}{*}{$\begin{array}{c}\geq 4 \text { Sucked seeds } \\
\text { per hole }\end{array}$} & \multirow{2}{*}{$\begin{array}{l}1 \text { Sucked seed } \\
\text { per hole }\end{array}$} & \multirow{2}{*}{$\begin{array}{l}2 \text { Sucked seeds } \\
\text { per hole }\end{array}$} & \multirow{2}{*}{$\begin{array}{c}3 \text { Sucked seeds } \\
\text { per hole }\end{array}$} \\
\hline & A & $\mathrm{B}$ & & & & & & \\
\hline 1 & 1 & 1 & 1.16 & 94.19 & 4.65 & 22.09 & 52.33 & 19.77 \\
\hline 2 & 1 & 2 & 2.74 & 90.41 & 6.85 & 26.03 & 44.10 & 20.28 \\
\hline 3 & 1 & 3 & 6.83 & 88.54 & 4.63 & 30.14 & 37.05 & 21.35 \\
\hline 4 & 2 & 1 & 0 & 93.41 & 6.59 & 23.08 & 47.25 & 23.08 \\
\hline 5 & 2 & 2 & 1.73 & 95.47 & 2.80 & 21.32 & 49.67 & 24.48 \\
\hline 6 & 2 & 3 & 0 & 97.50 & 2.50 & 22.50 & 52.75 & 22.25 \\
\hline 7 & 3 & 1 & 0 & 86.73 & 13.27 & 23.18 & 46.64 & 16.91 \\
\hline 8 & 3 & 2 & 1.01 & 89.90 & 9.09 & 29.29 & 44.44 & 16.17 \\
\hline 9 & 3 & 3 & 1.18 & 96.47 & 2.35 & 34.12 & 46.77 & 15.58 \\
\hline
\end{tabular}


The results show that under the negative pressure of $2.0 \mathrm{kPa}$, the probabilities of empty seed are less than $2 \%$. It indicates that the increase of the negative pressure for seed sucking can produce large suction force. In this condition, sucked seeds can overcome the disadvantage caused by the centrifugal force and inadequate suction force due to the random vibration. However, the forward speed of seeder slowing down (low speed of seeds suction plate) result in the centrifugal force and vibration reduction, but and the time needed for seed suction would increase. So the probabilities of 4 seeds would slightly increase and the probabilities of 1-3 seeds would slightly decrease. The qualified index is about $95 \%$, which can meet the seeding requirement of super hybrid rice. Thus, negative pressure of $2.0 \mathrm{kPa}$ is suitable for direct seeding under the high, medium and low speed.

The results indicated that under the negative pressure of $2.2 \mathrm{kPa}$, the probabilities of empty seed are less than $2 \%$ with value $0 \%, 1.01 \%$ and $1.18 \%$, respectively. Probabilities of $\geq 4$ per hole seeds increase under operational conditions of low speed and medium speed. It can be found that large negative pressure will increase the seed suction force and the probabilities of $\geq 4$ per hole. When increase forward speed of seeder, the rotation speed of seeds suction plate will be increased, the centrifugal force and vibration, so that the time of seed suction would be decreased. This would decrease the probabilities of $\geq 4$ seeds per hole. Thus, when the negative pressure was $2.2 \mathrm{kPa}$, the pressure could meet the requirement of high speed seeding, but it could not satisfy the demand of speed seeding at low and medium speed.

The forward speed of seeder would be changed by the specific circumstances of the paddy field. In order to meet the requirements of seeding at any speed with super hybrid rice, the negative pressure was set to $2 \mathrm{kPa}$ based on experimental results.

By the analysis of the pipeline, the pressure distribution in the pipeline is not uniform. The internal pressure of each seed metering device is inconsistent. It leads to inconsistent sowing precision of seed metering device. The sowing line chart of each seed metering device under different conditions was drew, as shown in Figure 8.

It can be seen from the Figure 8 that the average number of seeds per seed metering device decreases with the increase of the advance speed of the seeder. The average number of seeds of No.1 seed metering device, the No.6 seed metering device, the No. 2 seed metering device and the No.5 seed metering device, the No.3 seed metering device and the No.4 seed metering device are relatively close. It is shown that the corresponding pressure values are relatively close. And the average number of seeds in the middle seed metering devices was higher than that at both ends. The results showed that the air pressure values of the middle seed metering device are higher than that of both ends of the metering device. The longer the distance from the middle seed metering device is, the fewer the average number of grains per plant is. This result is consistent with the results obtained by the above pipeline test.
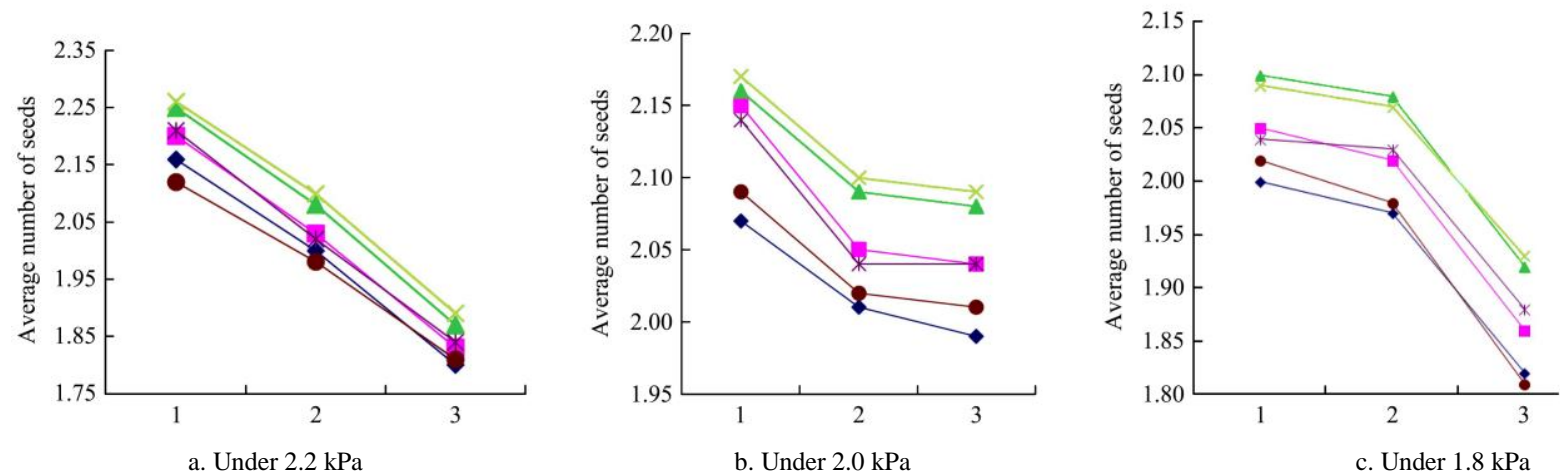

No.1 seed metering device - No.2 seed metering device

^-No.3 seed metering device - No. 4 seed metering device * No.5 seed metering device

- No.6 seed metering device

Note: Abscissa numbers of 1, 2 and 3 represent the forward speed of the seeder, which corresponds to the low, medium and high speed.

Figure 8 Average number of seeds

The hill spacing was measured and analyzed after seeding. Every 20 holes were taken as a group and eight groups were randomly selected. The results are provided in Table 4 . The probability of $150 \mathrm{~mm}$ 
distance is $43.8 \%$, and the probability between 130$170 \mathrm{~mm}$ distances is $93.8 \%$. The coefficient of variation is $9 \%(>5 \%)$ indicating a certain fluctuation. The main cause of uniform distribution of the hill spacing is that the difference of the field depth will lead to the random vibration of seeder. At the same time, dropping seeds that leave to seed metering device would be influenced by external environmental factors such as wind, so that the distribution of hill spacing could not be exactly distributed at the hill spacing of $150 \mathrm{~mm}$.

Table 4 Experiment results of hill spacing

\begin{tabular}{cccccccccccccc}
\hline Hill spacing/mm & 110 & 120 & 130 & 140 & 150 & 160 & 170 & 180 & 190 & 200 & Coefficient of variation \\
\hline Probability/\% & 0.6 & 3.1 & 11.9 & 20.6 & 43.8 & 11.2 & 6.3 & 1.3 & 0.6 & 0.6 & 9.0 &
\end{tabular}

The effect diagram of seeding on the field is shown in Figure 9. It can be observed that the hill spacing varied in certain scope, which could not be uniformly distributed. But the total amount of seeding was unchangeable in the field. Even the hill spacing just changed in a little fluctuation. The number of seeding holes per mu has not been changed. Because rice has strong self-adjust function, the capacities of tillers and seed setting effect were better in the large hill spacing than those in small hill spacing. Therefore, the growth and yield of rice could hardly be impacted by the hill spacing changing in a small range.

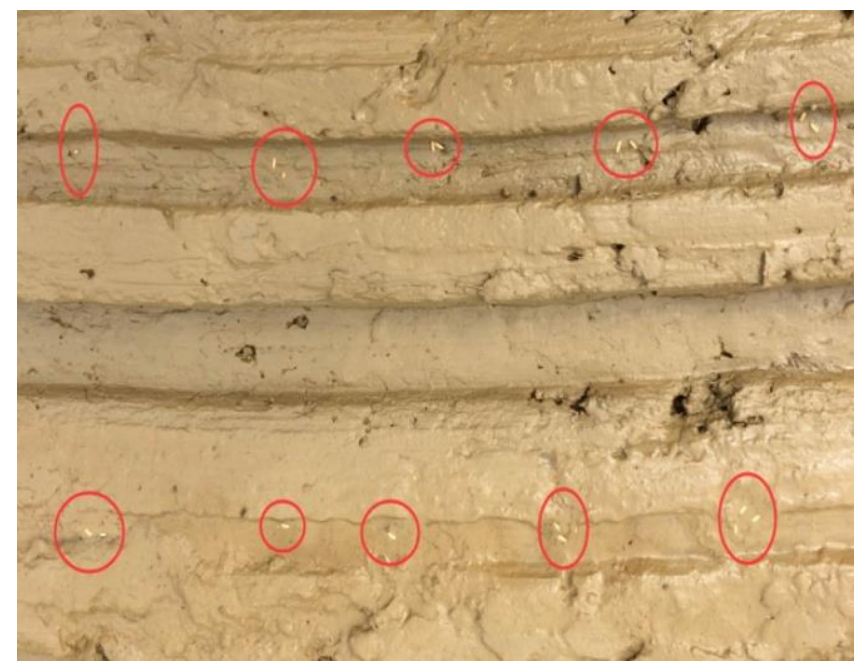

Figure 9 Effect diagram of field seeding (red circle for rice)

\section{Discussion}

\subsection{Pipeline experiment}

In this study, the integrated gasoline engine vortex-pump was used to provide air source for seed-metering device. The flow rate was $200 \mathrm{~m}^{3} / \mathrm{h}$. The normal working flow rate of single seed metering device was $24.2 \mathrm{~m}^{3} / \mathrm{h}$ based on the calculation above. The flow rate allows 8.2 seed-metering devices to work simultaneously. But, due to the complexity of the field condition, the whole flow rate would be occupied, with 8 seed-metering devices installed. This would influence the level adjustment of negative pressure. In that way, once seed-metering devices need higher negative pressure, the vortex-pump is not able to meet the requirement of working pressure for seed-metering devices. Therefore, 6 seed-metering devices were chosen.

The interval between every two seed-metering devices was $250 \mathrm{~mm}$, namely, the row spacing was $250 \mathrm{~mm}$. Thus, the total length of the pipeline was about $1250 \mathrm{~mm}$, which was relatively short. There is a slight difference between the pressure in sub-pipelines at the middle and the ends. The long pipeline increases the pressure losses, and lead to a big gap between pressure of seed metering devices in the middle and the end positions. Thus, it is important to design a reasonable pipeline structure with longer length, and ensure the uniform and stable pressure distribution when the length of pipeline increases. If this target can not be achieved by the design of the pipeline structure, throttle valve could be installed in the connection of each seed-metering device to solve this problem, by which the manufacturing costs of pneumatic rice direct seeder will be increased.

In this research, the diameter of the pipeline was $40 \mathrm{~mm}$. Based on fluid mechanics, when the fluid viscosity is constant, the pressure loss will decrease as the pipeline diameter increase. It means that an appropriate increase of pipeline diameter would reduce the pressure loss. Due to the limited size of the seed-metering device, the diameter of the pipeline should not increase excessively. The main reason is that the excessive increase of diameter of pipeline would lead to large diameter changes on the joint between the pipeline and 
seed-metering device, and increase the loss of local pressure.

According to the analysis above, the size of the pipeline structure and the interface of the seed-metering device need further study, to reduce the loss of air pressure and provide uniform and stable airflow for the pneumatic direct seeder.

\subsection{Field experiment}

The condition of the field is more complex than the condition of the laboratory. The aim of this research is to study the seeding of super hybrid rice, the seeding precision concentrating in the 1-3 seeds per hole. Considering the small amount of seeding, the seed-metering device needs further improvement to ensure the precision and yield. The hill spacing uniformity performance of a seeder is important for mechanical direct seeding ${ }^{[18-21]}$. The uniform seeds can avoid excessive internal competition when compared to random seeds. It is necessary to ensure the germination of seeds with small amount of the sowing, and it needs further research and analysis on the seed-injuring of seeder.

\section{Conclusions}

(1) A pneumatic rice direct seeder was designed by using the pneumatic rice seed-metering device.

(2) According to the requirement of flow rate for the single seed-metering device, the vortex pump was selected. The distribution of the air pressure was tested, and the uniformity and stability of the pressure distribution of pipeline were verified. The influential reasons of pipeline pressure loss were analyzed.

(3) Field experiment was conducted on pneumatic rice direct seeder. The effects of different negative pressure and different forward speed were analyzed. Optimal negative pressure was $2 \mathrm{kPa}$. The probabilities of 1-3 seeds per hole for the direct-seeder were $93.41 \%$, $95.47 \%$ and $97.50 \%$, respectively. Probabilities of empty seed were less than $2 \%$. The hill spacing was measured, and probability of the distance between them at $130 \mathrm{~mm}$ and $170 \mathrm{~mm}$ was $93.8 \%$. The growth and yield of rice would not be affected by a slight fluctuation of hill spacing.

\section{Acknowledgements}

Authors wish to thank the funding from 13th five-year plan National key research program (No. 2016YFD0200606), National Natural Science Foundation of China (No. 51105147), Foundation of Guangdong Province of China (No. S2011010001948), Commonweal Project (Project No. 201203059). We also thank the anonymous reviewers for their critical comments and suggestions for improving the manuscript.

\section{[References]}

[1] Yang Z Y, Li N, Ma J, Sun Y J, Xu H. High-yielding traits of heavy panicle varieties under triangle planting geometry: A new plant spatial configuration for hybrid rice in China. Field Crops Research, 2014; 168: 135-147.

[2] Farooq M, Siddique K H M, Rehman H, Aziz T, Lee D, Wahid A. Rice direct seeding: Experiences, challenges and opportunities. Soil \& Tillage Research, 2011; 111: 87-98.

[3] Peng S B, Yang J C. Current status of the research on high-yielding and high efficiency in resource use and improving grain quality in rice. Chinese Journal of Rice Science, 2003; 17(3): 275-280. (in Chinese)

[4] Luo X W, Jiang E C, Wang Z M, Tang X R, Li J H, Chen W T. Precision rice hill-drop drilling machine. Transactions of the CSAE, 2008; 24(12): 52-56. (in Chinese)

[5] Yang S, Liao Q X, Chen L, He L D. Distribution of rapeseed sowed by $2 \mathrm{BFQ}-6$ precision planter. Transactions of the CSAE, 2011; 27(11): 23-28. (in Chinese)

[6] Li B S, Li C H, Zhang X D. Virtual design and motion simulation of $2 \mathrm{BQ}$ suction precision seeder. Journal of Agricultural Mechanization Research, 2011; 5: 140-143. (in Chinese)

[7] Zhao J L, Jia H L, Jiang X M, Wang Y, Wang G, Guo H. Suction type offset double disc seed metering device of soybean seeder. Transactions of the CSAM, 2013, 44(8): 78-83. (in Chinese)

[8] Yasir S H. Design and test of a pneumatic precision metering device for wheat. Wuhan: Huazhong Agricultural University, 2011. (in Chinese)

[9] Singh R C, Singh G, Saraswat D C. Optimization of design and operational parameters of a pneumatic seed metering device for planting cottonseeds. Biosystems Engineering, 2005; 92(4): 429-438.

[10] Liao Y T, Wang L, Liao Q X. Design and test of an inside-filling pneumatic precision centralized seed-metering device for rapeseed. Int J Agric \& Biol Eng, 2015; 8(4): $10-18$. 
[11] Yazgi A, Degirmencioglu A. Measurement of seed spacing uniformity performance of a precision metering unit as function of the number of holes on vacuum plate. Measurement, 2014; 56(6): 128-135.

[12] Yazgi A, Degirmencioglu A, Onal I, Bayram E. Mathematical modeling and optimization of the performance of a metering unit for precision corn seeding. Journal of Agricultural Machine Science, 2010; 6(2): 107-113.

[13] Gaikwad B B, Sirohi N P S. Design of a low-cost pneumatic seeder for nursery plug trays. Biosystems Engineering, 2008; 99(10): 322-329.

[14] Guarella P, Pellerano A, Pascuzzi S. Experimental and theoretical performance of a vacuum seeder nozzle for vegetable seeds. Journal of Agricultural Engineering Research, 1996; 64: 29-36.

[15] St Jack D, Hesterman D C, Guzzomi A. Precision metering of Santalum spicatum (Australian Sandalwood) seeds. Biosystems Engineering, 2013; 115(3): 171-183.

[16] Karayel D. Performance of a modified precision vacuum seeder for no-till sowing of maize and soybean. Soil \& Tillage Research, 2009; 104(2): 121-125.

[17] Karayel D, Barut Z B, Ozmerzi A. Mathematical Modelling of Vacuum Pressure on a Precision Seeder. Biosystems Engineering, 2004; 87(4): 437-444.

[18] Karayel D, Wiesehoff M, Zmerz A O, Muller J. Laboratory measurement of seed drill seed spacing and velocity of fall of seeds using high-speed camera system. Computers and Electronics in Agriculture, 2006; 50(2): 89-96.
[19] Karayel D, Zmerzi O. Effect of forward speed on hill dropping uniformity of a precision vacuum seeder. Hort Technology, 2004; 14(3): 364-367.

[20] Ismet O, Degirmencioglu A, Yazgi A. An evaluation of seed spacing accuracy of a vacuum type precision metering unit based on theoretical considerations and experiments. Turkish Journal of Agriculture and Forestry, 2012; 36: 133-144.

[21] Ozmerzi A, Karayel D, Topakci M. Effect of sowing depth on precision seeder uniformity. Biosystems Engineering, 2002; 82(2): 227-230.

[22] Zhang G Z, Zang Y, Luo X W, Wang Z M, Zhang Q, Zhang S S. Design and indoor simulated experiment of pneumatic rice seed metering device. Int J Agric \& Biol Eng, 2015; 8(4): 10-18.

[23] Xing H, Zang Y, Wang Z M, Luo X W, Zhang G Z, Cao X M, et al. Design and experiment of filling seed stratified room on rice pneumatic metering device. Transactions of the CSAE, 2015, 31(4): 42-48. (in Chinese)

[24] Luo X W, Xing H, Zang Y, Wang Z M, Cao X M. A pneumatic rice direct seeder. Chinese Patent. $\mathrm{CH}$ 201610946757.9 (in Chinese)

[25] Cengel Y A, Cimbala J M. Fluid mechanics fundamentals and applications. McGraw-Hill Higher Education, 2013.

[26] GB/T 6973-2005 single (precise) test method. National Standards of the People's Republic of China. (in Chinese)

[27] Li Y Y, Hu C R. Experimental design and data processing. Beijing: Chemical Industry Press, 2008. (in Chinese) 